\title{
BMJ Open Association of prestroke medicine use and health outcomes after ischaemic stroke in Sweden: a registry-based cohort study
}

\author{
Lekander Ingrid (D) , ${ }^{1}$ Mia von Euler, ${ }^{2}$ Katharina S Sunnerhagen ${ }^{3}$
}

To cite: Ingrid L, von Euler M, Sunnerhagen KS. Association of prestroke medicine use and health outcomes after ischaemic stroke in Sweden: a registrybased cohort study. BMJ Open 2020;10:e036159. doi:10.1136/ bmjopen-2019-036159

- Prepublication history and additional material for this paper are available online. To view these files, please visit the journal online (http://dx.doi. org/10.1136/bmjopen-2019036159).

Received 03 December 2019 Revised 19 February 2020 Accepted 10 March 2020

A Check for updates

C Author(s) (or their employer(s)) 2020. Re-use permitted under CC BY-NC. No commercial re-use. See rights and permissions. Published by BMJ.

${ }^{1}$ Ivbar Institute AB, Stockholm, Sweden

${ }^{2}$ Department of Clinical Science and Education, Södersjukhuset, Karolinska Institutet, Stockholm, Sweden

${ }^{3}$ Institute of Neuroscience and Physiology, Rehabilitation

Medicine, University of

Gothenburg, Gothenburg,

Sweden

Correspondence to

Dr Lekander Ingrid;

ingrid.lekander@ivbar.com

\section{ABSTRACT}

Objective The objective was to investigate if there is a relationship between preischaemic stroke medicine use and health outcomes after stroke.

Setting This registry-based study covered Swedish stroke care, both primary and secondary care, including approximately $60 \%$ of the Swedish stroke cases from seven Swedish regions.

Participants The Sveus research database was used, including 35913 patients (33943 with full information on confounding factors) with an ischaemic stroke (International Classification of Diseases, 10th Revision (ICD-10) I63*) between 2009 and 2011 registered both in the regions' patient administrative systems and in the Swedish Stroke Register. Patients with haemorrhagic stroke (ICD-10 I61*) were excluded.

Primary outcome The primary outcome was the association, expressed in ORs, of prestroke medicine use (oral anticoagulants, statins, antihypertensives, antidepressants, non-steroidal anti-inflammatory drugs (NSAIDs) and antidiabetic drugs) and health outcomes 1 and 2 years poststroke (survival, activities of daily living dependency and modified Rankin Scale (mRS) 0-2), adjusted for patient characteristics and stroke severity at stroke onset.

Results The multivariate analysis indicated that patients on drugs for hypertension, diabetes, oral anticoagulants and antidepressants prestroke had worse odds for health outcomes in both survival (OR $0.65,95 \% \mathrm{Cl} 0.60$ to 0.69 ; OR $0.77,95 \% \mathrm{Cl} 0.71$ to 0.83 ; OR $0.72,95 \% \mathrm{Cl} 0.66$ to $0.80 ; \mathrm{OR} 0.91,95 \% \mathrm{Cl} 0.84$ to 0.98 , respectively, for survival at 2 years) and functional outcome (OR 0.82 , $95 \% \mathrm{Cl} 0.75$ to 0.89 ; OR $0.61,95 \% \mathrm{Cl} 0.55$ to 0.68 ; OR $0.83,95 \% \mathrm{Cl} 0.72$ to 0.95 ; OR $0.58,95 \% \mathrm{Cl} 0.52$ to 0.65 , respectively, for $\mathrm{mRS} 0-2$ at 1 year), whereas patients on statins and NSAIDS had significantly better odds for survival (OR 1.16, 95\% Cl 1.08 to 1.25 and OR $1.12,95 \% \mathrm{Cl} 1.00$ to 1.25 for 1-year survival, respectively), compared with patients without these treatments prior to stroke.

Conclusions The results indicated that there are differences in health outcomes between patients who had different common prestroke treatments, patients on drugs for hypertension, diabetes, oral anticoagulants and antidepressants had worse health outcomes, whereas patients on statins and NSAIDS had significantly better survival, compared with patients without these treatments prior to stroke.
Strengths and limitations of this study

- The study is based on registry data with good coverage of the population with confirmed stroke diagnosis, minimising the risk of selection bias.

- Combination of several data sources enables analyses of different health outcomes taking several confounding factors into account in multivariate regression analyses.

- Registry data always have limitations such as missing data, incomplete data and incorrect registrations.

- Potential confounding by indication.

- Data were not available on patient compliance to drug treatment or stroke aetiology.

\section{BACKGROUND}

Stroke affects almost 25000 patients each year in Sweden according to the Swedish Stroke Register. The risk factors of having a stroke are well known and established in literature, where higher age is associated with higher incidence. ${ }^{1}$ Men within the age group 45-75 years has also been shown to have higher incidence than women. ${ }^{1}$ Modifiable risk factors primarily relate to smoking and comorbidities, where hypertension, atrial fibrillation and diabetes are the three most common comorbidities increasing the risk for stroke. ${ }^{2}$

Generally, the use of prescription medicines is often an indicator of health as it reflects a person with comorbid conditions but may also reflect a medically well managed person. The increased risk of stroke associated with specific comorbidities can potentially be decreased with right management and treatment of these underlying diseases. Overall, oral anticoagulant (OAC) and aspirin treatment have shown to increase the risks of bleeding ${ }^{3}{ }^{4}$ while decreasing the risk of embolic and non-embolic ischaemic stroke, respectively. ${ }^{56}$ Diabetes is also a well established and modifiable risk factor for stroke, and specific clinical patterns of 
ischaemic stroke in individuals with diabetes have been identified such as higher frequency of lacunar infarct and hypertension. ${ }^{7}$ Depression is also a risk factor for stroke, ${ }^{8}$ where selective serotonin receptor inhibitors (SSRIs) are the most commonly used antidepressive drugs. Inhibition of serotonin in the platelets lead to an increased risk of bleeding and has been associated with increased risk of intracerebral haemorrhage. ${ }^{9}$ Current use of SSRI has also been shown to be associated with increased risk of ischaemic stroke. ${ }^{10}$ Use of non-steroidal anti-inflammatory drugs (NSAIDs), particularly the selective COX-2 inhibitors, has also been associated of a higher risk of stroke. ${ }^{11}$

Although studies have evaluated the association of these treatments with stroke incidence, the association with health outcomes after stroke is not as well established. The purpose of this study was therefore to investigate if there is a relationship between preischaemic stroke medicine use and health outcomes after stroke.

\section{MATERIAL AND METHODS \\ Sveus stroke research database}

The study was a retrospective registry-based study of patients with stroke in Sweden. The study population was retrieved from the Sveus stroke research database as part of the larger Sveus project (extensively explained elsewhere, www.sveus.se) ${ }^{12-15}$ The research database consisted of data from patients with acute stroke 2007-2012, identified in patient administrative systems (PAS) from seven Swedish regions (Jämtland-Härjedalen, Östergötland, Dalarna, Uppsala, Skåne, Stockholm and Västra Götaland), covering approximately $60 \%$ of all registered strokes annually in Sweden. PAS contain information on diagnosis and procedure codes related to all healthcare activities registered within the region. Adult patients $(>18$ years) with stroke were identified at inpatient admission with International Classification of Diseases, 10th Revision (ICD-10) codes I61* (intracerebral haemorrhage), I63* (cerebral infarction) and I64* (unspecified stroke), defined as index date. Data from all healthcare contacts during the study period were retrieved. Through the unique personal identification numbers and matching on index date, data for the identified patients were linked to data from the Swedish Stroke Register (health outcomes and patient characteristics), prescription drug registry at the National Board of Health and Welfare (dispensed drugs) and Statistics Sweden (date of death and level of education). These registries all have national coverage above $95 \%$. All data were anonymised after linkage of the different data sources, before being delivered to the research group.

\section{Study population}

The final study population consisted of 35913 patients acquiring an ischaemic stroke (ICD-10 code I63*) during 2009-2011, registered both in PAS and the Swedish Stroke Register. This allowed for 1 year of history prior to stroke and 2 years follow-up of health outcomes for the full study population. Index date was defined as the first inpatient admission at a unit treating acute stroke in PAS (ie, emergency, stroke unit, neurology or neurosurgical department).

- Patients residing in another region than where the acute stroke care was performed were excluded from the analysis to allow for complete follow-up.

- One patient could have more than one stroke within the study period if it occurred more than 28 days after the previous stroke, in line with definitions of new strokes in the Swedish Stroke Register.

- In the event a patient had several stroke diagnoses within the initial inpatient admission, a hierarchy was applied where I61>I63. Consequently, patients who had both diagnoses registered in PAS were not part of this study population. This definition of ischaemic stroke are in line with the Swedish Stroke Register.

\section{Study variables}

The study variables of interest were prescription drugs dispensed at pharmacies from six different groups of medicines. The dispensed prescriptions were identified through Anatomical Therapeutic Chemical (ATC) codes (see table 1).

A definition of a patient being on treatment was applied to the data for each of the groups above, defined as having dispensed two prescriptions within 1 year within one group of medicines. This is estimated both prior to (used in analysis) and after stroke (for descriptive purposes).

The health outcome variables of interest were estimated at 1 year and 2 years after stroke onset. The included data contained both patient-reported outcome measures from the Swedish Stroke Register and data on mortality from Statistics Sweden. The health outcome variables were (data source within parenthesis):

- Activities of daily living (ADL) independent 1 year after stroke, defined as not needing assistance with going to the toilet or dressing himself/herself (Swedish Stroke Register).

- Estimated modified Rankin Scale (mRS) 0-2 1 year after stroke. The Swedish Stroke Register does not collect mRS but contain variables that allow for estimating mRS based on algorithms by Eriksson $e t a l^{16}$ (Swedish Stroke Register).

- Survival 1 year after stroke based on all cause death date (Statistics Sweden).

- Survival 2 years after stroke based on all cause death date (Statistics Sweden).

\section{Statistical analysis}

Logistic univariate regression analyses were performed for each group of medicines and each respective health outcome. Thereafter, a multivariate analysis was performed of usage of all the different groups of medicines, while adjusting for confounding factors that previously have shown to have a large impact on health outcomes. ${ }^{13} 1417$ The confounding factors that the multivariate analysis adjusted for were (data source in parenthesis): 


\begin{tabular}{|c|c|c|}
\hline $\begin{array}{l}\text { Groups of } \\
\text { medicines }\end{array}$ & ATC code & \\
\hline \multirow[t]{3}{*}{$\begin{array}{l}\text { Oral } \\
\text { anticoagulants }\end{array}$} & B01AA03 & $\begin{array}{l}\text { Warafarin (vitamin } \mathrm{K} \\
\text { Antagonists) }\end{array}$ \\
\hline & B01AE07 & $\begin{array}{l}\text { Dabigatran (direct thrombin } \\
\text { inhibitors) }\end{array}$ \\
\hline & B01AF & Direct factor Xa inhibitors \\
\hline Statins & C10AA & HMG CoA reductase inhibitors \\
\hline \multirow{4}{*}{$\begin{array}{l}\text { Drugs used for } \\
\text { hypertension }\end{array}$} & $\mathrm{CO3}$ & Diuretics \\
\hline & $\mathrm{CO7}$ & Beta blocking agents \\
\hline & $\mathrm{C08}$ & Calcium channel blockers \\
\hline & C09 & $\begin{array}{l}\text { Agents acting on the renin- } \\
\text { angiotensin system }\end{array}$ \\
\hline \multirow[t]{5}{*}{ NSAIDs } & M01AB & $\begin{array}{l}\text { Acetic acid derivatives and } \\
\text { related substances }\end{array}$ \\
\hline & M01AC & Oxicams \\
\hline & M01AE & Propionic acid derivatives \\
\hline & $\mathrm{M} 01 \mathrm{AH}$ & Cyclo-oxygenase-2 inhibitors \\
\hline & M01AX & $\begin{array}{l}\text { Other antiinflammatory and } \\
\text { antirheumatic agents, non- } \\
\text { steroids }\end{array}$ \\
\hline \multirow[t]{4}{*}{ Antidepressants } & N06AA & $\begin{array}{l}\text { Non-selective monoamine } \\
\text { reuptake inhibitors }\end{array}$ \\
\hline & N06AB & $\begin{array}{l}\text { Selective serotonin reuptake } \\
\text { inhibitors }\end{array}$ \\
\hline & N06AG & $\begin{array}{l}\text { Monoamine oxidase A } \\
\text { inhibitors }\end{array}$ \\
\hline & N06AX & Other antidepressants \\
\hline \multirow{3}{*}{$\begin{array}{l}\text { Drugs used in } \\
\text { diabetes }\end{array}$} & A10A & Insulins and analogues \\
\hline & $\mathrm{A} 10 \mathrm{~B}$ & $\begin{array}{l}\text { Blood glucose-lowering drugs, } \\
\text { excluding insulins }\end{array}$ \\
\hline & A10X & Other drugs used in diabetes \\
\hline
\end{tabular}

ATC, Anatomical Therapeutic Chemical code; HMG CoA reductase, 3-hydroxy-3-methylglutaryl coenzyme A reductase; NSAIDs, non-steroidal anti-inflammatory drugs.

- Sex (PAS).

- Age (PAS).

- ADL dependency prior to stroke (Swedish Stroke Register).

- Accommodation prior to stroke (Swedish Stroke Register).

- Consciousness at arrival (Swedish Stroke Register), proxy for stroke severity due to poor coverage of National Institutes of Health Stroke Scale (NIHSS) in the Swedish Stroke Register.

- Level of education (Statistics Sweden).

A multivariate logistic regression was performed for dichotomous outcomes, while continuous data were analysed using ordinary least squares regression. The full set of predictors was used in all regression models. STATA
Table 2 Patient characteristics prior to stroke

\begin{tabular}{|c|c|c|}
\hline & Value & $\mathbf{N}$ \\
\hline Age (mean, SD) & $76.5(12.16)$ & 35913 \\
\hline Men (\%) & 50.0 & 35910 \\
\hline Higher eduction (>12 years) (\%) & 16.5 & 35035 \\
\hline Living alone (\%) & 51.3 & 35536 \\
\hline Type of accomodation (\%) & 100.0 & 35464 \\
\hline $\begin{array}{l}\text { Living at home with no home } \\
\text { help service }\end{array}$ & 71.8 & \\
\hline $\begin{array}{l}\text { Living at home with home help } \\
\text { service }\end{array}$ & 18.8 & \\
\hline Special housing & 9.3 & \\
\hline ADL dependent (\%) & 11.3 & 35127 \\
\hline $\begin{array}{l}\text { Level of conciousness at hospital } \\
\text { arrival (\%) }\end{array}$ & 100.0 & 35378 \\
\hline Fully awake & 85.7 & \\
\hline Lethargic & 10.9 & \\
\hline Unconscious & 3.4 & \\
\hline
\end{tabular}

ADL, activities of daily living; $n$, number of patients with information on this variable.

V.13.1 was used for statistical analyses. Analyses were performed without adjustment for multiple comparisons.

In the statistical analyses, the population consisted of 33493 patients in total, who had full information on confounding factors.

\section{Patient and public involvement}

A patient representative from the Swedish Stroke Association participated in the Sveus research group. The Sveus research group together defined relevant indicators of interest for the stroke population, limited by data availability, in the set-up of the Sveus research database. This current study is an extension of the initial work of the Sveus research group, adding analyses and perspectives on the predefined indicators.

Anonymous patients have contributed to this study by participating in the national registries, with an optout possibility. No other patient or public representatives were involved in the design, conduct, reporting or dissemination plans of this research.

\section{RESULTS}

\section{Study population}

Table 2 summarises the characteristics of the patient population. A majority of the patients were living at home without home help service and were ADL independent prior to the stroke. The vast majority were also awake at arrival to the hospital.

The results indicated that there was an increase in proportion of patients taking drugs for hypertension, OACs and statins after stroke compared with prior to stroke (figure 1). These findings were expected as they 


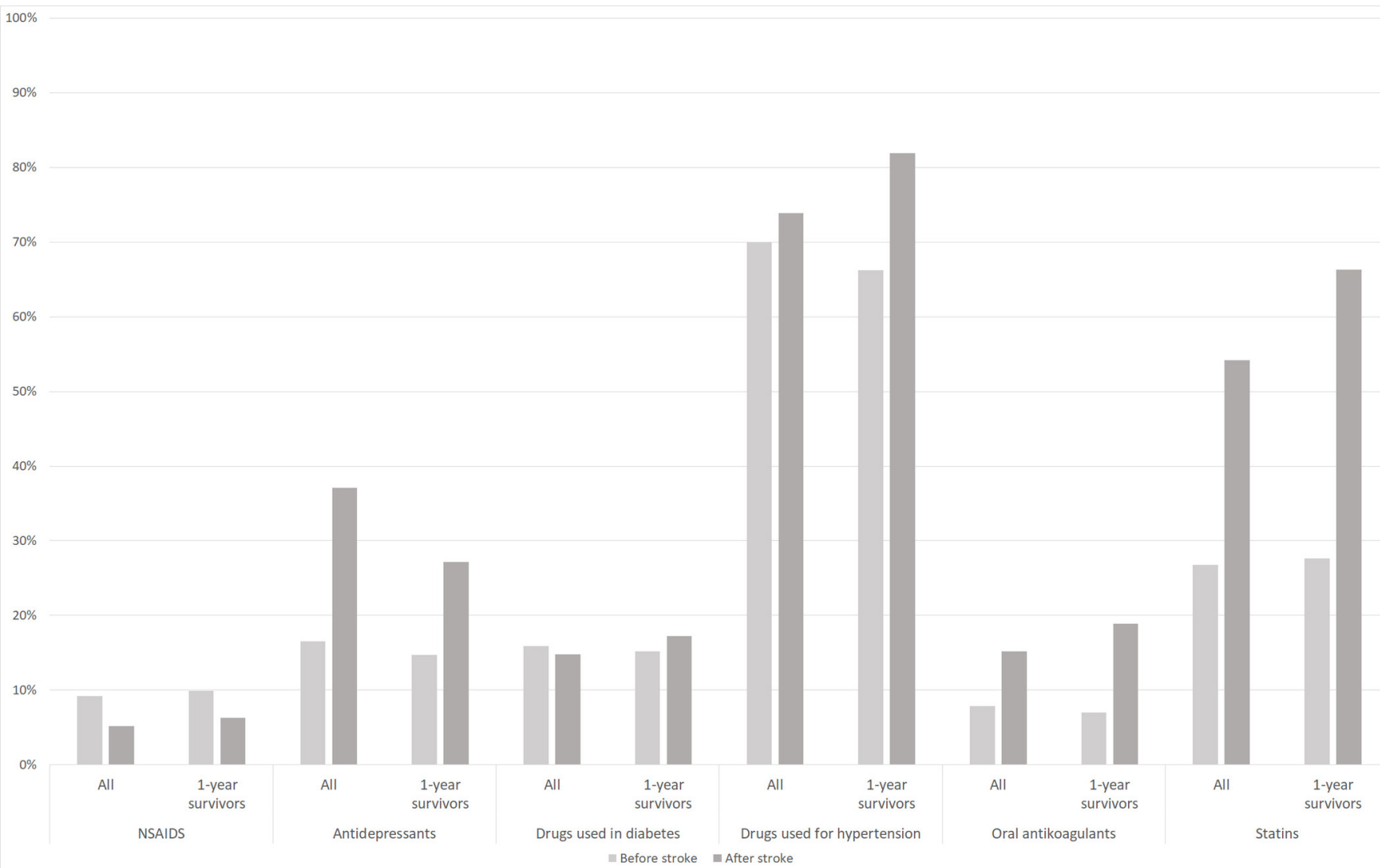

Figure 1 Proportion of patients on treatment for different causes the year prior to and after stroke. All incident cases $(n=35913)$ and patient surviving 1 year poststroke $(n=27587)$. NSAIDs, non-steroidal anti-inflammatory drugs.

are in line with treatment recommendations. The results further indicated that there was an increase in proportion of patients taking antidepressants, whereas the use of NSAIDs decreased (figure 1) after stroke compared with prior to stroke. The same prescription pattern is detected both for the population of incident cases and the population surviving 1 year (complete follow-up). The most commonly prescribed group of medicines were drugs used for hypertension, followed by statins, both before and after stroke.

\section{Health outcomes}

Overall, $77 \%(\mathrm{n}=27587)$ of the patients were still alive 1 year poststroke. For these patients, ADL-independence and mRS was estimated based on data from the Swedish Stroke Register, with approximate coverage of $70 \%$ of the

\begin{tabular}{lllc}
\hline Table 3 Health outcomes & & & \\
\hline & $\begin{array}{l}\text { Proportion } \\
(\%)\end{array}$ & N & $\begin{array}{l}\text { Coverage } \\
\text { (\%) }\end{array}$ \\
\hline ADL independent at 1 year & 83.22 & 19140 & $69^{\star}$ \\
mRS 0-2 at 1 year & 58.16 & 18734 & $68^{\star}$ \\
Survival 1 year & 76.82 & 35913 & 100 \\
Survival 2 years & 69.36 & 35913 & 100 \\
\hline
\end{tabular}

${ }^{*}$ Coverage based on patients surviving 1 year poststroke.

ADL, activities of daily living; mRS, modified Rankin Scale. surviving patients (table 3 ). The results indicated that the majority of surviving patients were ADL-independent and had an estimated mRS of $0-2$, that is, good functional ability, 1 year post stroke.

\section{Univariate analysis}

The results from the univariate analysis indicated that patients on OACs, drugs for hypertension, antidepressants or drugs for diabetes before stroke had worse health outcomes compared with those without any of these therapies (table 4). Patients who had statins or NSAIDs prior to stroke had higher survival, but non-significant difference on level of ADL-independence and mRS 0-2, compared with those patients without these therapies.

\section{Multivariate analysis}

The results from the multivariate regression analysis are presented in figure 2 (numbers in online supplementary table 1 ). The results indicated a clear relationship between patient characteristics and the health outcomes of interest, with all significant ORs (95\% CIs). Older age, lower educational level, ADL dependency, dependency on home help/special housing prior to stroke as well as worse level of consciousness at hospital arrival were all associated with worse health outcomes.

Most of the results from the univariate analyses of association between medication use and health outcomes prevailed after adjusting for confounding factors. After 
multivariate regression analysis, patients who were taking drugs for hypertension before stroke onset had lower odds for favourable health outcomes in all dimensions (survival 1 year: OR $0.66,95 \%$ CI 0.61 to 0.71 ; survival 2 years: OR $0.65,95 \%$ CI 0.60 to 0.69 ; ADL independent 1 year: OR $0.87,95 \%$ CI 0.79 to 0.97 ; mRS $0-21$ year, OR $0.82,95 \%$ CI 0.75 to 0.89 ) as well as for patients using diabetes drugs (survival 1 year: OR $0.79,95 \%$ CI 0.73 to 0.86 ; survival 2 years: OR $0.77,95 \%$ CI 0.71 to 0.83 ; ADL independent 1 year: OR $0.69,95 \%$ CI 0.62 to 0.78 ; mRS $0-21$ year: OR $0.61,95 \%$ CI 0.55 to 0.68$)$. The same pattern was detected for patients on OACs (survival 1 year: OR 0.70, 95\% CI 0.63 to 0.77 ; survival 2 years: OR $0.72,95 \%$ CI 0.66 to 0.80 ; ADL independent 1 year: OR $0.92,95 \%$ CI 0.78 to 1.07; mRS 0-2 1 year: OR $0.83,95 \%$ CI 0.72 to 0.95 ) and antidepressants (survival 1 year: OR $0.95,95 \%$ CI 0.88 to 1.04; survival 2 years: OR $0.91,95 \%$ CI 0.84 to 0.98 ; ADL independent 1 year: OR $0.69,95 \%$ CI 0.61 to 0.77 ; mRS 0-2 1 year: OR $0.58,95 \%$ CI 0.52 to 0.65 ), however not reaching statistical significance for all health outcomes (ADL independence and 1-year survival, respectively) after adjusting for confounding factors.

The results for patients on statins or NSAIDs prior to stroke remained after multivariate analysis; that is, they had a higher odds of survival both at 1 year (OR 1.16, 95\% CI 1.08 to 1.25 and OR $1.12,95 \%$ CI 1.00 to 1.25 , respectively) and 2 years poststroke (OR $1.15,95 \%$ CI 1.08 to 1.23 and OR 1.13 , 95\% CI 1.02 to 1.25 , respectively), but no statistical association was identified for the odds of ADL independence (OR 0.99, 95\% CI 0.90 to 1.10 and $\mathrm{OR} 0.97,95 \% \mathrm{CI} 0.84$ to 1.11 , respectively) or mRS 0-2 (OR 1.03, 95\% CI 0.94 to 1.12 and OR 0.98 , $95 \%$ CI 0.87 to 1.11 , respectively). Notably, patients on NSAIDs prior to stroke had higher odds of ADL independence or mRS 0-2 in univariate analysis but lower odds in the multivariate analysis, although none of these results reached statistical significance.

\section{DISCUSSION}

Previous studies on prestroke treatment have often been conducted based on a subpopulation of the total stroke population or evaluating the association to stroke incidence or severity. This current study took a more holistic approach to the stroke population and based on a patient sample of 33493 patients with full information on confounding factors, estimated the association between prestroke treatment and health outcomes 1 year and 2 years after ischaemic stroke. The multivariate analysis indicated that patients on drugs for hypertension, diabetes, OACs and antidepressants had worse health outcomes, whereas patients on statins and NSAIDS had significantly higher survival, compared with patients without these drug treatments prestroke.

\section{Stroke severity}

Several studies have investigated the impact of prestroke treatment on stroke severity, which in turn is a strong 

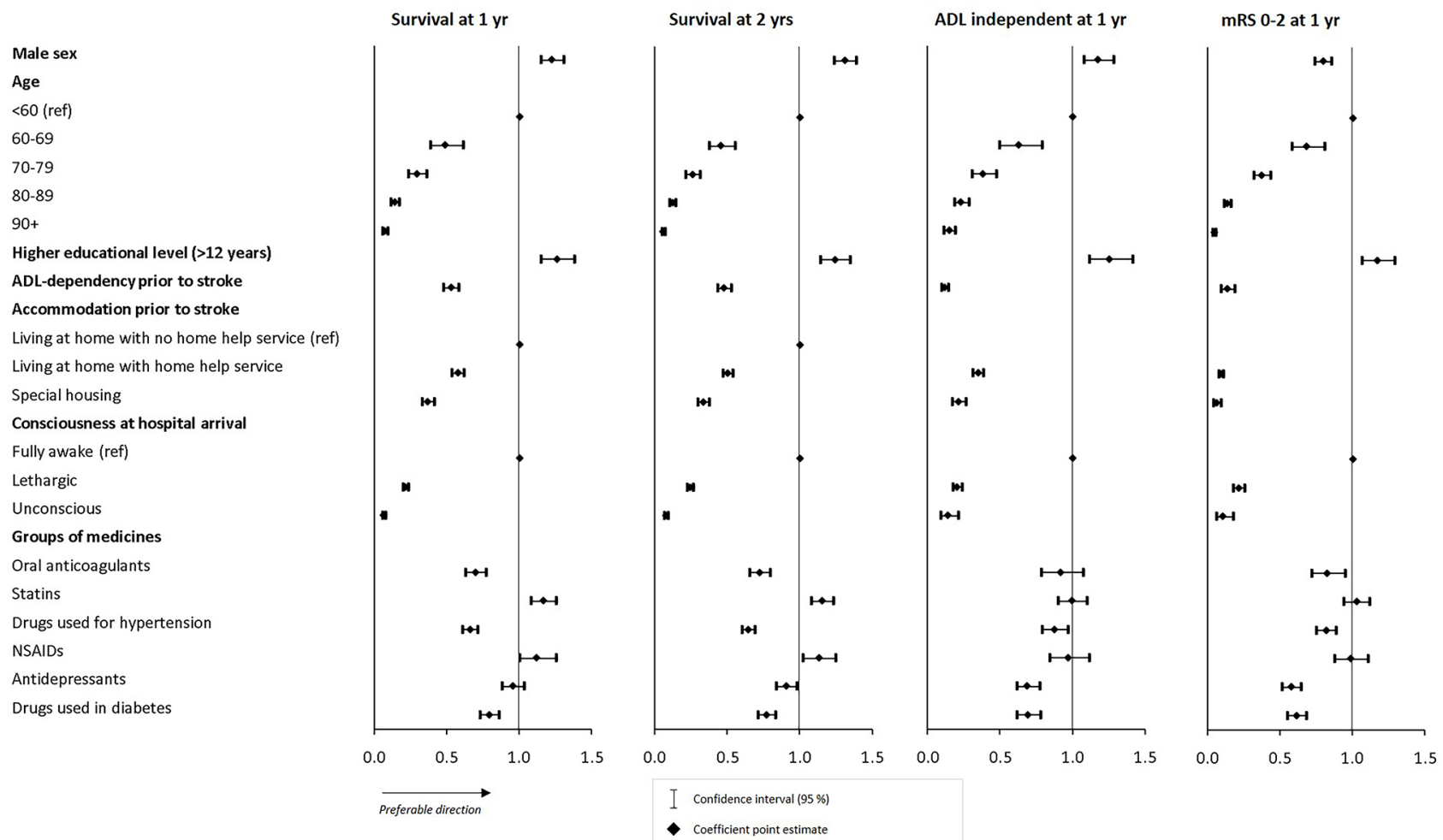

Figure 2 Results from multivariate regression analysis. ADL, activities of daily living; mRS, modified Rankin Scale; NSAIDs, non-steroidal anti-inflammatory drugs.

indicator of the final health outcome. For example, studies have indicated that prestroke hypertension treatment is associated with milder strokes, ${ }^{18}$ as well as prestroke statin use. ${ }^{19}$ Other studies have not identified any statistical association between prestroke treatment with hypertension treatment ${ }^{19}{ }^{20}$ or OACs and stroke severity. ${ }^{191}$ In this current study, the association between prestroke treatment and outcomes have been adjusted for differences in stroke severity in the multivariate model, isolating the association to longer-term health outcomes. Level of consciousness was used to adjust the results for stroke severity, which has been shown to be a strong predictor of health outcome. ${ }^{17}$ Another option would have been to use NIHSS as measure of stroke severity, which is a validated stroke severity scale that has been shown to be a strong predictor of health outcome. ${ }^{22}{ }^{23}$ However, the coverage of NIHSS in the Swedish Stroke Register was too low to be used (approximately 50\%), and therefore, level of consciousness was used instead. This variable has, however, been shown to be a good approximation of the full NIHSS in predictions ${ }^{24}$ and therefore provide valid adjustment in the multivariate analysis.

\section{Previous studies}

Outcome after stroke, ischaemic or haemorrhagic, in patients treated with OACs, platelet inhibitors or other agents with an antithrombotic effect is of interest as an increasing part of the stroke population are using these drugs. At the time of our data extraction, the use of non-vitamin $\mathrm{K}$ antagonist oral anticoagulants (NOACs) were still limited. However, studies have indicated that there is no difference in risk for mortality in warfarin compared with NOAC-treated patients with ischaemic stroke after adjustment for confounders, ${ }^{25}$ indicating that the results from this study may still be valid today. Previous studies regarding association of anticoagulant treatment prestroke and health outcomes poststroke present inconclusive results. A systematic review of anticoagulant treatment at onset of atrial fibrillation-related stroke and its association with functional outcomes, conclude that prestroke treatment had a favourable association with functional outcome and survival. ${ }^{26}$ These findings are supported by Illán-Gala et $a l^{27}$ indicating that preischaemic stroke use of OACs was associated with favourable functional outcomes (mRS 0-2 at 3 months). Other studies have not been able to show any significant association of prestroke warfarin use on functional health outcomes $(\mathrm{mRS})^{28}$ or indicating worse survival both for patients treated with warfarin only, as well as those with untreated atrial fibrillation. ${ }^{29}$ The present study indicated worse health outcomes in terms of survival for patients treated with OACs prior to stroke, whereas the association with functional outcome was not significant. These results may potentially indicate that these patients also are at a worse health condition prior to stroke.

Patients presenting with ischaemic stroke in atrial fibrillation have previously been shown to have a risk reduction of worse health outcomes after stroke ${ }^{30}$ and better survival $^{31} 32$ if they had used statins prestroke. These findings are in line with the findings in our study with regards to mortality, although this study is not limited to 
patients with atrial fibrillation. Studies of the association of preischaemic stroke statin use on short-term functional outcome is however inconclusive, with evidence of not significantly influencing the short-term functional outcome ${ }^{33}$ whereas others have shown a favourable association. ${ }^{34}$ This present study did not find any statistically significant association to functional outcome, adding to these inconclusive results. Additionally, continuous statin use after stroke in addition to prestroke treatment has been found favourable for health outcomes. ${ }^{33}$ Most patients on statin use prior to stroke also continued with statins after stroke in this study as well.

Several studies have indicated that there is no significant association of prestroke antihypertensive treatment and health outcomes ${ }^{202135}$ but untreated hypertension trended for more unfavourable outcome compared with those on treatment. ${ }^{21}$ On the contrary, this present study indicated that patients on hypertensive treatment had worse health outcomes, both in terms of functional outcome and survival. Differences in results may partly be explained by adjustment for stroke severity in our study, a larger patient sample and inclusion of total patient population and not only patients with hypertension (treated vs untreated). Several previous studies have indicated that the observed decreased mortality in stroke over time can be explained by better primary preventions, especially of hypertension. ${ }^{236} 37$ This can possibly be explained by findings that hypertensive treatment is also associated with milder strokes. ${ }^{18}$

The literature is rather scarce regarding the association of prestroke treatment for depression and diabetes as well as NSAID use with health outcomes poststroke. Results regarding prestroke SSRI and health outcomes are conflicting. Studies have indicated that prestroke treatment with SSRI did not have any association with functional outcome or survival, ${ }^{38}{ }^{39}$ whereas other studies have indicated a negative association with health outcomes ${ }^{40}$ and others a positive association. ${ }^{41}$ On the contrary, poststroke use of SSRI is suggested to ameliorate outcome after ischaemic stroke as shown in several studies. ${ }^{42}$ This present study indicated worse functional outcome for patients on antidepressants prior to stroke but did not find any significant association with survival.

Patients with diabetes, both treated and untreated prior to stroke, have been shown to have worse survival. ${ }^{29}$ These findings are in line with the findings of this current study, where patients on treatments for diabetes prestroke had worse outcomes both in terms of functional outcome and survival.

\section{Strengths and limitations}

The criteria for a patient being 'on treatment' in this study was two dispensed prescriptions within a group of medicines within the year prior to stroke. This definition was examined in a sensitivity analysis to determine how many patients were missed compared with allowing only one dispensation. For all groups except NSAIDs, the criteria of two dispensations captured $85 \%-96 \%$ of the population who had dispensed any prescription of the specific group of medicines during the year. However, for NSAIDs, almost $50 \%$ of the patients were missed using the chosen criterion. NSAIDs are more likely to be used for shorter treatment periods, whereby these results are in line with expectations. Additionally, non-prescribed NSAIDs were not included in the database, whereby short-term usage of NSAIDs were not part of the analysis.

A limitation of using dispensation data is that information on patient compliance is missing. Adding data on patient compliance to dispensed medicines would increase the accuracy of the 'on treatment' definition, but this information was not available in the registries. However, using dispensation data is one step closer to patient use compared with prescription data. ${ }^{43}$ Specification of stroke aetiology was also missing, which would have given more precise information on the nature of the stroke event.

A major strength of this study was the large patient sample, representing the vast majority of the patients who had a stroke during 2009-2011 in the included regions. The sample represents the majority of the total Swedish ischaemic stroke population, although generalisations to other regions or countries should be done with caution. The data were taken from regional or national registries, which all have good coverage of the stroke population, providing high coverage of the datapoints included. These registries are generally of good quality, but the results may be affected by missing data, incorrect registrations or incomplete data. The variations were, however, deemed to be minor. Health outcomes were based on national data on date of death (for survival) and patient reported outcomes as collected by the Swedish Stroke Register. The latter were collected through questionnaires that were sent out to the patients 1 year after their stroke, providing a coverage of approximately $70 \%$ of the surviving patients. Additionally, for some patients who had a stroke, these questions were completed by their next of kin, possibly giving other results than if the patient would have answered themselves. These patients were most likely severely impaired after stroke, which may give rise to systematic errors.

We chose to exclude patients with diagnoses of both ischaemic and haemorrhagic stroke. The rationale for this was to ensure that we only analysed patients who had an ischaemic stroke. However, in doing this, patients who had (often large) ischaemic strokes with haemorrhagic transformation who have a poorer outcome may have been excluded.

There is a risk of confounding by indication as there is a potential association between the underlying diseases (for which the medicines are prescribed) and health outcomes. Previous studies have also indicated that patients not receiving treatment are more frail and have more comorbidities than those who get treatment, ${ }^{44}$ whereas in some cases it may be the opposite, that is, that sicker patients have more medications. An interpretation of the causal effect of medication use on health outcomes 
cannot be done based on these results. Such conclusions warrant another study design, such as a randomised clinical trial or a case-control study. The choice of study design for this study was limited by the data availability within the Sveus stroke research database, and a casecontrol design would require information and subjects that were not available, for example, controls that did not have a stroke. Another option would have been to select a subpopulation, for example, patients with previous hypertension, and only evaluate hypertensive treatments. This would instead only provide insights to a small part of the total patient population and not account for all the treatments that are common within the ischaemic stroke population.

This present study was limited to the association between prestroke treatments and health outcomes. Variations in poststroke treatments may, however, also have an effect on deviating results in final health outcomes.

\section{CONCLUSIONS}

The results of this present study have indicated that there are differences in health outcomes between patients who had different common prestroke treatments. Prestroke treatment with drugs for hypertension, diabetes, OACs and antidepressants were all associated with worse outcomes post ischaemic stroke and may serve as a special prompt to ensure acute and preventative stroke treatments are thoroughly applied.

Acknowledgements We acknowledge the previous work with data management of the Sveus research database performed by Carl Willers and Patrik Sandin. We also acknowledge the Sveus research collaboration and the Sveus stroke research group (including representatives from the Swedish Stroke Association), the Swedish Stroke Register and all patients and their caregivers contributing with their data.

Contributors All authors have contributed to the design of the study. LI has performed all statistical analyses, interpretation of results and main writing of the manuscript. KSS and MvE have validated the results, contributed with clinical perspective on interpretation of results and writing of manuscript as well as its final approval.

Funding This work was supported by the Swedish Research Council (VR201700946) and by grants from the Swedish state under the agreement between the Swedish government and the county councils, the ALF agreement (ALFGBG718711), The Swedish Heart-Lung Foundation, The Swedish Brain Foundation, Promobilia. The work was further supported by Sveus, a research collaboration in which seven Swedish regions develop systems for value-based monitoring and reimbursement of healthcare. The publication of study results was not contingent on the sponsors approval or censorship of the manuscript.

Competing interests $\mathrm{LI}$ is employed by Ivbar Institute, a research company specialised in health carehealthcare governance and analysis of health carehealthcare data. Remaining coauthors did not declare any conflicts.

\section{Patient consent for publication Not required.}

Ethics approval Ethical approval for the study was granted by the Regional Ethical Review Board in Stockholm, Sweden (2013/1541-31/5 and 2016/785-32), with no additional requirements on the research group to gather patient consent. All methods were carried out in accordance with relevant guidelines and regulations.

Provenance and peer review Not commissioned; externally peer reviewed.

Data availability statement The data that support the findings of this study is available from each registry holder (as stated in the manuscript), but legal restrictions apply to the availability of these data and are therefore not publicly available. Access to data will require ethical approval and approval from each registry holder.
Open access This is an open access article distributed in accordance with the Creative Commons Attribution Non Commercial (CC BY-NC 4.0) license, which permits others to distribute, remix, adapt, build upon this work non-commercially, and license their derivative works on different terms, provided the original work is properly cited, appropriate credit is given, any changes made indicated, and the use is non-commercial. See: http://creativecommons.org/licenses/by-nc/4.0/.

ORCID iD

Lekander Ingrid http://orcid.org/0000-0002-7332-4036

\section{REFERENCES}

1 Harmsen P, Wilhelmsen L, Jacobsson A. Stroke incidence and mortality rates 1987 to 2006 related to secular trends of cardiovascular risk factors in Gothenburg, Sweden. Stroke 2009;40:2691-7.

2 Wolf PA. Risk factors for stroke. Stroke 1985;16:359-60.

3 Connolly SJ, Eikelboom J, Joyner C, et al. Apixaban in patients with atrial fibrillation. N Engl J Med 2011;364:806-17.

4 Mant J, Hobbs FDR, Fletcher K, et al. Warfarin versus aspirin for stroke prevention in an elderly community population with atrial fibrillation (the Birmingham atrial fibrillation treatment of the aged study, BAFTA): a randomised controlled trial. Lancet 2007;370:493-503

5 Rothwell PM, Algra A, Chen Z, et al. Effects of aspirin on risk and severity of early recurrent stroke after transient ischaemic attack and ischaemic stroke: time-course analysis of randomised trials. Lancet 2016;388:365-75.

6 Tereshchenko LG, Henrikson CA, Cigarroa J, et al. Comparative effectiveness of interventions for stroke prevention in atrial fibrillation: a network meta-analysis. J Am Heart Assoc 2016;5:11.

7 Chen R, Ovbiagele B, Feng W. Diabetes and stroke: epidemiology, pathophysiology, pharmaceuticals and outcomes. Am J Med Sci 2016;351:380-6.

8 O'Donnell MJ, Chin SL, Rangarajan S, et al. Global and regional effects of potentially modifiable risk factors associated with acute stroke in 32 countries (INTERSTROKE): a case-control study. Lancet 2016;388:761-75.

9 Douros A, Ades M, Renoux C. Risk of intracranial hemorrhage associated with the use of antidepressants inhibiting serotonin reuptake: a systematic review. CNS Drugs 2018;32:321-34.

10 Trifirò G, Dieleman J, Sen EF, et al. Risk of ischemic stroke associated with antidepressant drug use in elderly persons. J Clin Psychopharmacol 2010;30:252-8.

11 Tacconelli S, Bruno A, Grande R, et al. Nonsteroidal antiinflammatory drugs and cardiovascular safety - translating pharmacological data into clinical readouts. Expert Opin Drug Saf 2017;16:791-807.

12 Lekander I, Willers C, Ekstrand E, et al. Hospital comparison of stroke care in Sweden: a register-based study. BMJ Open 2017;7:e015244.

13 Lekander I, Willers C, von Euler M, et al. Relationship between functional disability and costs one and two years post stroke. PLoS One 2017;12:e0174861.

14 Willers C, Lekander I, Ekstrand E, et al. Sex as predictor for achieved health outcomes and received care in ischemic stroke and intracerebral hemorrhage: a register-based study. Biol Sex Differ 2018;9:11.

15 Willers C, Sunnerhagen KS, Lekander I, et al. The association of pre-stroke psychosis and post-stroke levels of health, resource utilization, and care process: a register-based study. Front Neurol 2018;9:1042.

16 Eriksson M, Appelros P, Norrving B, et al. Assessment of functional outcome in a national quality register for acute stroke: can simple self-reported items be transformed into the modified Rankin scale? Stroke 2007;38:1384-6.

17 Appelros P, Terént A. Characteristics of the National Institute of health stroke scale: results from a population-based stroke cohort at baseline and after one year. Cerebrovasc Dis 2004;17:21-7.

18 Selim M, Savitz S, Linfante I, et al. Effect of pre-stroke use of ACE inhibitors on ischemic stroke severity. BMC Neurol 2005;5:10.

19 Desmaele S, Cornu P, Barbé K, et al. Relationship between prestroke cardiovascular medication use and stroke severity. Eur J Clin Pharmacol 2016;72:495-502.

20 De Raedt S, Haentjens P, De Smedt A, et al. Pre-Stroke use of betablockers does not affect ischaemic stroke severity and outcome. Eur $\checkmark$ Neurol 2012;19:234-40.

21 Vibo R, Kõrv J, Roose M. One-Year outcome after first-ever stroke according to stroke subtype, severity, risk factors and pre-stroke 
treatment. A population-based study from Tartu, Estonia. Eur J Neurol 2007:14:435-9.

22 Appelros P. Prediction of length of stay for stroke patients. Acta Neurol Scand 2007;116:15-19.

23 Koton S, Bornstein NM, Tsabari R, et al. Derivation and validation of the prolonged length of stay score in acute stroke patients. Neurology 2010;74:1511-6.

24 Bray BD, Campbell J, Cloud GC, et al. Derivation and external validation of a case mix model for the standardized reporting of 30day stroke mortality rates. Stroke 2014:45:3374-80.

25 Komen JJ, Forslund T, Mantel-Teeuwisse AK, et al. Association of preceding antithrombotic therapy in atrial fibrillation patients with ischemic stroke, intracranial hemorrhage, or gastrointestinal bleed and mortality. Eur Heart J Cardiovasc Pharmacother 2019. doi:10.1093/ehjcvp/pvz063. [Epub ahead of print: 26 Oct 2019].

26 Hannon N, Arsava EM, Audebert HJ, et al. Antithrombotic treatment at onset of stroke with atrial fibrillation, functional outcome, and fatality: a systematic review and meta-analysis. Int J Stroke 2015;10:808-14.

27 Illán-Gala I, Martínez-Sánchez P, Fuentes B, et al. Effect of anticoagulation on cardioembolic stroke severity, outcomes and response to intravenous thrombolysis. J Thromb Thrombolysis 2016:42:99-106

28 Zhu J, Ma M, Guo Y, et al. Pre-Stroke warfarin enhancement of collateralization in acute ischemic stroke: a retrospective study. BMC Neurol 2018;18:194.

29 Wolfe CDA, Smeeton NC, Coshall C, et al. Survival differences after stroke in a multiethnic population: follow-up study with the South London stroke register. BMJ 2005;331:431.

30 Ko D, Thigpen JL, Otis JA, et al. Influence of statin therapy at time of stroke onset on functional outcome among patients with atrial fibrillation. Int J Cardiol 2017;227:808-12.

31 Kotlęga D, Gołąb-Janowska M, Meller A, et al. Beneficial effects of pre-stroke statins use in cardioembolic stroke patients with atrial fibrillation: a hospital-based retrospective analysis. Arch Med Sci 2019;15:385-92.

32 Flach C, Elstad M, Muruet W, et al. The impact of pre- and poststroke statin use on stroke severity and long-term outcomes: a population-based cohort study. Cerebrovasc Dis 2019;47:260-7.

33 Ishikawa H, Wakisaka Y, Matsuo R, et al. Influence of statin pretreatment on initial neurological severity and short-term functional outcome in acute ischemic stroke patients: the Fukuoka stroke Registry. Cerebrovasc Dis 2016;42:395-403.

34 Choi JC, Lee JS, Park TH, et al. Effect of pre-stroke statin use on stroke severity and early functional recovery: a retrospective cohort study. BMC Neurol 2015;15:120.

35 Eizenberg Y, Grossman E, Tanne D, et al. Pre admission treatment with beta-blockers in hypertensive patients with acute stroke and 3-month outcome-Data from a national stroke Registry. J Clin Hypertens 2018;20:568-72.

36 Caplan LR. Caplan's stroke: a clinical approach. Cambrige university press, 2009.

37 Woo D, Haverbusch M, Sekar P, et al. Effect of untreated hypertension on hemorrhagic stroke. Stroke 2004;35:1703-8.

38 Schellen C, Ferrari J, Lang W, et al. Effects of SSRI exposure on hemorrhagic complications and outcome following thrombolysis in ischemic stroke. Int J Stroke 2018;13:511-7.

39 Mortensen JK, Larsson H, Johnsen SP, et al. Impact of prestroke selective serotonin reuptake inhibitor treatment on stroke severity and mortality. Stroke 2014;45:2121-3.

40 Etherton MR, Siddiqui KA, Schwamm LH. Prestroke selective serotonin reuptake inhibitor use and functional outcomes after ischaemic stroke. Stroke Vasc Neurol 2018;3:9-16.

41 Siepmann T, Kepplinger J, Zerna C, et al. The effects of pretreatment versus de novo treatment with selective serotonin reuptake inhibitors on short-term outcome after acute ischemic stroke. J Stroke Cerebrovasc Dis 2015;24:1886-92.

42 Gu S-C, Wang C-D. Early selective serotonin reuptake inhibitors for recovery after stroke: a meta-analysis and trial sequential analysis. $J$ Stroke Cerebrovasc Dis 2018;27:1178-89.

43 Skeppholm M, Friberg L. Adherence to warfarin treatment among patients with atrial fibrillation. Clin Res Cardiol 2014;103:998-1005.

44 Loikas D, Forslund T, Wettermark B, et al. Sex and gender differences in thromboprophylactic treatment of patients with atrial fibrillation after the introduction of non-vitamin $\mathrm{K}$ oral anticoagulants. Am J Cardiol 2017;120:1302-8.

45 Forslund T, Wettermark B, Wändell P, et al. Risks for stroke and bleeding with warfarin or aspirin treatment in patients with atria fibrillation at different CHA(2)DS(2)VASc scores: experience from the Stockholm region. Eur J Clin Pharmacol 2014;70:1477-85. 